\title{
The emergence of creative practice as research
}

Abstract: The term 'Creative Practice as Research' is now in common usage in the tertiary sector, although it is relatively new in its inception. This article traces the rise of the term (and its variations), which emerged about the same time as the tertiary auditing processes, such as Aotearoa New Zealand's Performance-Based Research Fund (PBRF). But creative practitioners had already been sneaking production into the traditional university, at times facing resistance and even derision from scholars undertaking more conventional research within the arts, humanities and social science departments. The author argues that the term Creative Practice as Research, and the many practices under its umbrella such as journalism, is now widely accepted, in part because it has been convenient, fulfilling particular needs within a changing tertiary landscape. Its greater acceptance allows traditional universities to respond to student demand for skills-based learning without losing their reputation for research excellence. But the term also suits the former polytechnics, or 'new universities', that are eager to imbue their craft and technical teaching history and practice with richer research content. Drawing on a new wave of 'production studies', the article also explores how a specific instance of Creative Practice, the documentary, does indeed fulfil the requirement of research as articulated through other academic disciplines such as the social sciences. Furthermore, documentary and other creative practices can contribute to 'impact', an increasingly important metric deployed in the assessment of research within the tertiary sector.

Keywords: academic disciplines, creative practice, creative practice as research, documentary, journalism, New Zealand, PBRF, Performance-Based Research Fund, polytechnics, skills-based learning, tertiary sector

\section{ANNIE GOLDSON \\ University of Auckland}

HE phrase Creative Practice as Research (CPR) is heard frequently these
days within universities, so much so it appears to be part of the natural lin-
go, even though it is an expression that is relatively new. ${ }^{1}$ CPR argues that
creative processes, rather than being a supplement or 'nice to have', contribute
just as much 'new knowledge' as the more traditional approaches to research,
at least in arts and social sciences, which involves publishing in monographs, 
journal articles and edited collections. Although now CPR is accepted within the academy, complex tensions can still arise in its implementation. Arguments arise about what practices qualify, and which do not. Frictions also arise between Creative Practice produced within universities and their respective 'cultural industries' in the broader cultural community.

I draw on documentary production as an example of CPR as it is my own speciality. A growing number of PhD students also include documentary in the new wave doctorates that have a practice component. The genre has always fitted in relatively easily to academia as, in the words of Bill Nichols, documentary is one of the 'discourses of sobriety' that claim to describe the 'real', to tell the truth, along with science, economics, politics, and history (2001, p. 39). That he sidelines documentaries affective, metaphorical or expressive tendencies is a debate for another day. But as well as finding a place, or not, within academia, all Creative Practice has an industry counterpart. Documentary's counterpart, in my experience, has been the screen industries - that is, film, television, the art world and digital industries. But this can vary. Documentary can also be positioned as a branch of journalism, the focus of this journal, which looks more towards news, current affairs, and again digital industries as its home profession. That I include digital industries in both lists points to an overlap between documentary and journalism, even their merging, something I have addressed in an earlier article in this publication (Goldson, 2015) but given my experience, I place it here within the screen industries

\section{The documentary relationship with the academe and screen industries}

Documentary produced with a university setting, as with all Creative Practice, can have a patchy relationship with the screen industries 'out there'. Is university-based Creative Practice intended to challenge or 'make a difference' to mainstream industries, engendering a kind of critical thinking associated with the social sciences and humanities? Or do practitioners exist in the academy to offer mere training to the new generation of industry workers? These positions may not be poles apart as many in the creative industries acknowledge they require reinvigoration, but very often the mainstream remains focused on producing the 'hit'. Generally, the screen industry has tended to have little interest in what is occurring in production among university practitioners. This could be in part because Aotearoa New Zealand has relatively few university staff nation-wide are involved in producing and teaching screen production, so they and their work are not particularly visible. But as Jon Dovey states, 'By and large, the screen industries have tended to see higher education as just a site for training future personnel rather than undertaking creative research' and that they focused almost entirely on filling gaps in their workforce (2009, p. 53).

Not all disciplines face this complex dichotomy. Some have always had 
practice components, for example, the sciences, engineering, medicine or architecture. But these tend to follow, as Dovey (2009, p. 51) suggests, a kind of triangulation - idea-development-'product to market'-pursuing a streamlined track in tandem with the professional sectors in their respective fields. Fine arts, performance, and music have also fared better than the media arts, given the more secure material relations they have with their constitutive areas, where there are more established traditions to draw upon and indeed, fall back on. As argued above, Creative Practice as Research, produced variably in the arts, humanities and social sciences disciplines - the pools within which many of us swim - can have an altogether stickier relationship with their industry counterparts. But they also have had a complicated relationship with the academy, which I will now explore.

Pinpointing when the terminology Creative Practice (and its variants) first arrived is hard. Still, its emergence appears aligned with the introduction of university research assessment processes that shifted the economic basis of universities away from depending mainly on a student numbers model (EFTS, or bums-on-seats) to one that also rewarded the collective research output of the staff. In Aotearoa New Zealand, the Tertiary Education Commission (TEC) instituted the Performance-Based Research Fund (PBRF) in 2003, following the formation of Britain's United Kingdom's Research Excellence Framework (REF) and Australia's Excellence for Research in Australia (ERA). Differing from its precursors, PBRF focused on the outputs of individual researchers which are then aggregated into an overall score. Each researcher produces an Evidence Portfolio that cites published Research Outputs (NROs) and collates instances of Peer Esteem. The Tertiary Educational Commission offers up a concise description of the reason for PBRF:

The purpose of the Performance-Based Research Fund (PBRF) is to ensure that excellent research in the tertiary education sector is encouraged and rewarded. This means assessing the research performance of tertiary education organisations (TEOs) and then funding them on the basis of their performance. ${ }^{2}$

It is safe to say PBRF has had a transformative effect on institutional life, providing a chunk of university and tertiary provider budgets. The auditing process has altered the shape and frequency of research outputs so that they are timed to suit its six-year cycle. Some academic staff are less willing to take on duties, either teaching or administration, recognising that their standing and promotion prospects are likely to be tied to their PBRF score. The auditing process has also injected more competition into an already competitive sector, becoming not just about the allocation of resources but also a de facto struggle for the crown. As a consequence, the resources spent in the run-up to PBRF are mighty, given the 
person-hours, the rehearsals and the intensity of the practice runs.

But the PBRF has generated positive outcomes too, increasing the focus on the importance of research generally and accelerating the acceptance of Creative Practice within the academy. Practitioners demanded that our work be recognised as research once we realised the auditing processes were underway. Some creative and practice disciplines have fared better than others, however. Documentary production slipped into the Creative Arts sector relatively unquestioned, seen as part of Screen production. Journalism practice-as-research has struggled for visibility, either included as part of journalism studies, which belongs to the Communication/Media Studies discipline or as 'creative non-fiction', an add-on to creative writing. Given its affiliation with documentary, the fate of journalism practice-as-research is worth considering in more depth here. In an article written before the 2018 PBRF round, David Robie pointed out that the audit process 'makes no explicit provision for journalism practice-as-research, although it does not exclude it either' (2015). But as the author points out, journalism educators at various universities are now focusing less exclusively on practitioner-based instruction and undertaking quality academic research. Thus, Robie, who was a member of the Social Sciences panel for PBRF in 2016-7, argues that the TEC should open up the door to investigative journalism and other long-form modes. But he also puts the onus on journalism educators who need 'to push the boundaries for greater acceptance of journalism research methodologies and to claim an enhanced academic space as a "critic and conscience of society"' (2015). In Australia, the battle for journalism practice-as-research to be accepted in the ERA process has been fiercer, led by scholars such as Chris Nash who argues, like Robie, that there is a pressing need for journalism research methodologies to be recognised (2017). Nash sheets blame home not just to the auditing processes but also to the 'academy, including its journalist members, and not of its leading practitioner members' (2017, p. 26). In his book on the subject of journalism, Nash focusses on I.F.Stone and Hans Haacke's respective practices as exemplars of journalistic excellence, exhibiting methodological rigour and conceptual reflexivity (2016). Wendy Bacon, an investigative journalist, former professor at UTS (Sydney) and currently editor of the Frontline section of this journal, has for some time advocated for more interface between professional journalism and scholarly journalism research practices (2012, p.153). In a submission to Australian and NZ standard research classification review where journalism's fate hung in the balance, Bacon argued that 'in-depth, rigorous journalism practice can produce fresh insights and knowledge and has methodologies that can and should be recognised' $(2020$, p. 3). As I suggest later in this article concerning documentary, Bacon points out that journalism can similarly share methodologies with sociology and history - hence is distinct from the priorities of media studies or journalism studies. While she recognises research about journalism 
is valuable, she suggests it does not encompass what journalism research can or should be $(2019$, p. 2).

I have been a member of the Creative and Performing Arts panel for PBRF three times since 2003, most recently in 2018. The CPA panel assesses portfolios representing a diverse range of practices, including fine arts photography, curatorial practices, film-making (narrative, documentary, animation and experimental), creative writing, music, design and computer graphics, theatre, but also their theoretical counterparts, art history, theatre studies, musicology, and production studies of various stripes. Some individual researchers offer up Evidence Portfolios that contain creative outputs exclusively, while others are a blend of practice and theory. Luckily for those of us in the field, the CPA has had exemplary leadership, headed by scholars and creatives committed to their practice and to the institutions they work within. The two Chairs I have had the pleasure of working with, who come from music and fine arts respectively (thus have the more 'secure tradition' connections I refer to above), have taken as given that creative practice is a legitimate form of research within the University system. They have used the PBRF process to emphasise this firmly-held position and consistently argued that creative practice deploys critical thinking and 'new knowledge' just as well as more traditional methods of research. One can read, in their insistence, some frustration that this recognition by academic institutions has been a long time coming.

This positive attitude towards Creative Practice has given a fillip and more certitude to those producing a range of non-traditional outputs within the academy. There are always arguments during evaluative processes, and our PBRF panel grappled with a series of questions about practice within the academy. Where does 'acceptable' creative practice begin and end? Where does the 'research' bit come in, and when is creative practice work-a-day? How does one ascertain the relative weight of a contribution, especially when roles within collaborative projects are so often intertwined? How does the wealth and investment of an institution, or lack thereof, impact on an evidence portfolio? What personal circumstances may affect the frequency or quality of an individual's research outputs? Long-term panel members have also witnessed the shifts in the assessment process. PBRF has had to respond to changes within disciplines and curricula, as well as to the profound impact technological change has had on research outputs, not only in a formal sense but critically how research is now 'published' and circulated.

The impact of PBRF has led to a greater acknowledgement of the many ways that cultural production engages with and indeed extends, audiences, readers and spectators. The term 'creative practice' is now routinely listed in university paperwork, for example, in grant applications or PBRF preparation documents. However, the acceptance of creative works within the arts and humanities has been a relatively long time coming - and has involved some fractious debate. 
Some thorny issues remain. The Ethics process is one-its requirements, for example, to be very open with one's participants precludes any form of investigative documentary or journalism (How, for instance, can you investigate corruption in the City Council if you are open to all councillors?). What about the acknowledgement of the effort required to raise significant external funding to cover the costs of production of 'high impact' documentary or drama which can take years? And should funding be awarded, there is consistent pressure to cycle income through the university — which then clips the ticket. Dispersing external funding is fair enough in principle, given the support universities provide their staff, but spawns some further complexities. Academic business units cannot fulfil the specialist tasks filmmakers require, and budgets anyway are already lean. Besides, funnelling funding from one state agency (a film funder) to another (the university), let alone dealing with international co-production funding, would cause impossible headaches.

\section{Exploring the history of Creative Practice as Research}

To explore the history of Creative Practice as Research, I turn here to my career, which has been more shaped by luck and happenstance than planning. We will all have our tales to tell and of course, what follows is a partial, personal take rather than a comprehensive look at the gradual institutional acceptance that has taken place. I had gone to New York City in the early 1980s having worked as a journalist at Radio New Zealand but wanting to move into film-making — which I did.

At the time I was producing 'video art', labelled as such first because of exciting developments in video technology which made cameras sufficiently affordable and portable (just) to be lugged around, by artists and political activists alike. Second, my artistic and political circles, mobilised by the Reagan administration's policies, saw documentary as a conventional genre associated with mainstream television. The commercial underpinnings of television made it, we argued, incapable of nurturing aesthetic experimentation or accommodating the alternative political viewpoints we tended to share. The televisual exceptions were little pockets within the public broadcasting system (PBS) and also within cable TV, then the newcomer challenging the hegemony of broadcast television. As part of the deal allowing cable TV to roll out, a small number of public access cable channels had been established. They aired more local, noncommercial, uncensored programming and series such as Paper Tiger TV and Deep Dish TV, produced by volunteer collectives of media producers, educators and activists flourished. ${ }^{3}$ I joined these collectives, but I also attended various workshops that were abundant in the city during those times. At the same time, I completed an MA in Film Studies (then relatively new as a discipline) at New York University. I began teaching myself at Global Village, a kind of video branch of the New School for Social Research, famously founded by members 
of the Frankfurt School as a centre for teaching philosophy and social sciences. Teaching, to me, appeared a more stable and ethical way of making a living than working in commercials, or the newly-minted music video business, both of which seemed rife with sexism among other unpleasant-nesses. I had made some short pieces of video art, gained a minor reputation in the local art work/ film circuit in NYC, had my MA and done my teaching. These qualifications managed to get me hired as a junior lecturer at Brown University, part of the prestigious Ivy League chain of institutions and based a few hours north of NYC in Providence, Rhode Island. Brown was small and sufficiently elite to be able to be experimental and progressive when it chose and offered film and video production within the then Semiotics Department - which was to become the Department for Modern Culture and Media. I taught video production, a mix of documentary and experimental work, but also pushed myself into the field of theory - feminist theory, semiotics, cultural studies and related disciplineswhich was the primary focus of the curriculum.

On the practical front, my efforts to master 'theory' (to use a blanket term) was in part because I found it engaging and challenging. But academia was shaping up as a possible career move for me, not just a lucky break. If academia was to see me as more than 'just a filmmaker', I felt I needed to diversify my teaching. Universities provided some shelter for less commercial filmmakers, buffering us from the prerogatives of the mainstream industry, providing an income and permitting, even encouraging, an intellectual engagement that could be difficult to achieve 'out there'.

I continued teaching across the academic/creative divide when I returned to Aotearoa New Zealand in the mid-1990s, taking up a post in the English Department at the University of Auckland, teaching in a film studies strand of the broader discipline. It was then that I first taught video production in Aotearoa New Zealand, to a third-year documentary class which has seen many graduates produce extraordinary projects and advance into careers in the industry and at universities. But I also continued my academic teaching and decided to undertake a $\mathrm{PhD}$ which I completed in 2006, while simultaneously keeping up my various documentary film-making projects. In pursuing a conventional doctorate, which was all then that was on offer, I was, in part, seeking validation from the academy. At this point, documentary production was still not accepted as research. Some that considered themselves 'true scholars' expressed some indifference or scepticism, challenging production's right to exist within such an institution. Was filmmaking too commercial, not really academic enough, too populist? Not really research? There was at very least a hierarchy. There was pressure of filmmakers to engage with complex theory, while more traditional scholars knew very little about the technologies of production. As Dovey states, screen practitioners felt some resentment as it was assumed that 'everyone should know how to speak 
abstract critical analytic discourse whilst knowing how to frame a shot or make a cut is relegated to a subaltern specialist discourse' $(2009$, p. 59).

In time, film studies expanded to media studies and cultural studies, and shortly thereafter, we departed from the English Department to become a department ourselves. Tempers flared at times. At the University of Auckland, I recall a member of a research committee accusing Roger Horrocks, who had introduced the popular strand of film studies, of wanting funding to 'watch television' or ' $g o$ to film festivals'. But production offerings in the curriculum grew and screen-writing and then drama directing were added to documentary production, forming a Screen pathway, but one that always occupied a 'boutique' status within the academic programme.

In many ways, Creative Practice as Research then described by the humbler umbrella term 'production', snuck into the traditional universities, often introduced by one or two people, practitioners themselves. This move faced resistance from some quarters, but support from others. Production often remained an awkward fit as institutional life was still structured to accommodate more conventional disciplines.

As well as settling in at the traditional universities, CPR has also found a home at the 'new universities', the former polytechnics. In the UK, and many of the Commonwealth countries, including in Aotearoa New Zealand and Australia, polytechnics were 'upgraded' into universities in the 1980s and 1990s, often doing the heavy-lifting in terms of overall student expansion, absorbing and encouraging students from less affluent communities to enter the tertiary sector. Auckland University of Technology, over the road from the University of Auckland, offers a good example. Formerly Auckland Technical Institute, then said to offer 'advanced vocational training', including a popular practical journalism course, it became Auckland Institute of Technology when it earned the right to confer degrees. Finally, in 2000, it became the first polytechnic to become a university and was rebranded Auckland University of Technology. AUT's background as a technical college meant its focus would have been on craft and vocational skills. Its transformation into a university suggests that theory and critical theory/analysis would have been introduced into this core curriculum over time, supplementing its more practical base and increasing its research focus. I imagine this shift and change was disruptive, just as the introduction of production had been into the University of Auckland. My understanding is that RMIT University in Melbourne and the University of Technology Sydney (UTS) have followed similar trajectories and like AUT, are successful examples of the shift from polytechnics to universities.

Although now mostly welcomed as a legitimate form of research, Creative Practice emerged in part because of economic factors. As university education has become more expensive, parents and students raise valid questions about 
its worth. Who can afford a university education without falling into economic doldrums? Will there be job opportunities for the media studies graduates, the sociologists and the art historians? These anxieties and perceptions made the idea of learning practical or creative skills appealing to students, as they may be perceived, rightly or wrongly, as offering up more job possibilities on graduation. Furthermore, students live in a much more mediatised world and creativity and production is woven into their everyday life. Thus Creative Practice as Research became a convenient moniker within a traditional university setting, one way of addressing the developing student interest in technical and skills-based learning but without relinquishing the underpinning notion of research quality aligned with the history of the academy. Creative practice as research, as a concept, did offer a way out of a dilemma- how to provide an education that is popular with the students, but that still fits relatively comfortably within a university agenda.

For the newer university model, such as AUT's, the university emerging out of a technical college or polytechnic, the term CPR also proved useful. Its deployment allowed the redubbing and rebuilding of the technical and craft skills that were part of its history, taking them out of the regular work, craft or skills framework into something more academic. The institution could then earn its badge as a university. The new universities have been disadvantaged by the PBRF process, given the traditional institutions were more able to draw on their histories as research institutions. But there is something of a meet-in-the-middle process going on here. The conventional university embraces Creative Practice as Research to satisfy student demands for concrete skills while retaining its academic reputation for research. But the former polytechnics can own the phrase too, as a way of repositioning and elevating its solid skills-based history into more of a research culture that enhances its standing.

It may be cynical to suggest that the greater acceptance of Creative Practice within the academy was motivated by pragmatic reasons alone, a response to either student demand or the need to attract funding. There is, of course, more recognition and appreciation of the contribution that Creative Research makes to culture, that of the university and at large. Many staff have 're-tooled' and descriptions of research areas included in job applications have expanded to include creative research. These shifts suggest there is undoubtedly a greater understanding of the skills required to deliver a 'research rich' creative culture and a recognition of how mediatised the world is, and perhaps always has been.

\section{Producing creative work within the academy}

Producing creative work within the academy has many advantages. A stable income is a luxury many working in creative fields are unable to achieve, and research funding can assist in seeding projects, or sometimes cover their costs completely. Teaching is a rewarding career for most. We learn from our students 
as they learn from us, forging productive collaborations.

A vibrant research environment enhances a creative work, providing access to smart and specialised colleagues, let alone libraries, databases and specialist archives, and an association with a university can open many doors. But there can also be complications, around workloads, ethics clearances and funding conundrums as I mentioned above. There are possible intellectual and creative fishhooks too, one such being the pressure to align their outputs with current academic analyses, or critiques of culture, resulting in work that can feel derivative. When I was first working as a filmmaker within the academy, anxieties about practice often loomed large. Rather like the term 'politically correct' then used as a self-deprecating term by activists - so 'theoretically correct' was a term used to judge a work in terms of the dictates of academia of the time. The divisions within the feminist film movement, sometimes coded the 'feminist realist debates' offer a good example. Critiques of the representation of women within Hollywood films, articulated by Laura Mulvey in her seminal article, (1975) led to demands that the codes of realism must be smashed if women were to be liberated from libidinal inequalities that held their power in check. 'Realism', it was said, reinforced the dodgy concept of the 'unified subject', so must be smashed if a feminist cinema were to be born anew (Johnston, 1973). These were exciting and challenging theories, yet as Alex Juhasz recalls (1999) out the window too went much feminist activist documentary which had the nerve to be 'realist'. Many feminist filmmakers shifted to more reflexive practices, obeying the strictures of the feminist orthodoxy of the time. Some notable films, documenting second-wave feminism and its many gains, simply disappeared, forcing new generations of feminist filmmakers to reinvent the wheel. Countercinema prevailed within university curricula, one of the only ways that more marginal film practices could survive. Juhasz encapsulates the contradictions:

When I view 1970s (and 1980s and 1990s) realist talking heads documentaries by feminists and other disenfranchised producers, and, perhaps more significantly, as I make a video with groups of political women, I am struck by two things: how often political producers are drawn to realist strategies and then, in contradiction, how often such work is evaluated by academics in an overly critical and sometimes simplified manner. (1999, p. 193)

The strictures imposed, or self-imposed, on producers by theory and theorists now appears more relaxed, although a resurgence of identity politics is leading to kind of cultural policing, that reminds me of the 1980s. But there have been positive intellectual developments too recently seen in the rise of what is called generically 'production studies', academic investigations that explore processes of production and creative practice. This literature departs from the plethora of 'how-to' books that circulate in the marketplace. Production studies, an exploration of producing 
as a broad field, use 'ethnographic, sociological, critical, and political-economic methods' to explore media production, from major producers to lowly production assistants, connecting 'cultural activities to an understanding of media and texts' (Mayer, Banks, \& Caldwell, 2009). ${ }^{4}$ There has been a parallel rise in screen writing studies, with publications such as the Journal of Screenwriting established to 'encourage the investigation of a broad range of possible methodologies and approaches to studying the scriptwriting form' including looking at histories, providing contextual analyses, exploring the processes of writing and so forth. ${ }^{5}$

Michael Wayne (2008) in a similar fashion has extended the study of documentary out from the more historical, ontological and textual analyses pioneered by Bill Nichols (1983, 2001), Michael Renov (1993) and Jane Gaines (1999) among others. Wayne explores documentaries as 'critical and creative research', exploring 'a trinity of terms as they pertain to the documentary: critical, creative, research' $(2008$, p. 82). His article asks what it means to discuss documentary as a mode of research, that is, to what extent its critical methodologies overlap with issues around knowledge production associated with the social sciences. As he argues, documentary often deploys quantitative methods of statistical analysis and graphics familiar to sociologists. A documentary on climate change might chart how fast the ice-caps have been melting, whereas a feminist film might list how few women occupy boardrooms or political office. But documentary, as Wayne argues, is even more closely aligned with the use of qualitative methodologies given films are often based on the 'case study, inductive analysis, the inferred typicality from the particular'(2008, p. 94). Qualitative methods include the interview, a staple of the documentary, but also very much part of social science research; the use of narration, which is equivalent to a researcher's analysis of their findings; or the inclusion of archive, a research strategy shared by historians and sociologists alike. As well as exploring documentary as a critical practice aligned with sociology and like disciplines, Wayne also asks what it means to discuss documentary as a creative practice, one in which aesthetics plays a crucial role in its production and consumption. All of the more 'academic' methods cited above can be mobilised in very different ways, using, for example, a reflexive, surrealist, poetic, humorous or expository approach. Creativity and imagination are essential elements of any kind of cultural production. Wayne quotes Marcuse as stating that these qualities provide an ability to create something new out of given materials of cognition (Wayne, 2008, p. 92). Creativity, in other words, can fuse thinking and feeling.

In this 'audit era', Creative Practice as Research may have an advantage over more traditional modes of publication. Practitioners in the media arts, certainly those reliant on external funding, are already attuned to audience outreach not only because we want our work to be heard and seen, but that funding agencies require us to develop distribution plans. Thus, we are acutely aware of our 
work's 'impact', a measure that is becoming central to the auditing processes, such as RAI and PBRF. 'Impact' can be difficult to ascertain and how it might affect research of all stripes is unknown. Creative practitioners already walk a tightrope. To fulfil academic requirements, we need to demonstrate our films contribute 'new knowledge' to a field. Yet at the same time, they need to be sufficiently 'commercial' to attract the kinds of external funding that we so often need in the production process.

A new awareness of the importance of 'impact' however, may be providing new resources for Creative Practice. Documentaries, podcasts, even animation films are being built into application bids as part of larger research projects, for example, Health Research Council of New Zealand (HRC) or the Australian Research Council (ARC). Their inclusion suggests a recognition that creative projects, as well as being research outputs in their own right, can enhance more scholarly research as they have the potential to be distributed through mainstream media channels as well as through academic networks. Thus, they are able, potentially at least, to reach much bigger audiences than traditional research outputs, attracting more to the project as a whole.

Such is the case with The Conquistador, the Warlpiri and the Dog Whisperer, a podcast or 'crafted audio storytelling documentary' as its producer Siobhán McHugh, from the University of Wollongong, describes it (2019, p. 1). Funded as part of an ARC grant on art history, the podcast explores 'significant but littleknown cross-cultural relationships', that influence the production of Aboriginal art today, an important economic and cultural activity (McHugh, 2019, p. 1). As McHugh describes

sound, as well as speech, expresses aspects of the community ... (t)he holistic audio artefact allows us to appreciate at many levels, including the sensory, the cross-cultural dimensions of Indigenous art production - and in choreographing these sound recordings into a layered, affective, creative work, I am creating not just an engaging and accessible documentary, but a scholarly 'non-traditional research output (NTRO). (McHugh, 2019, p.1).

I realise that I, like McHugh, have long made a similar argument about my films being NTROs, or as we call them in our PBRF system, NROs-but not so overtly as she has. I have published multiple academic articles about the documentary, exploring it either as a genre (Goldson, 2015) or more commonly, analysing my specific films. At the time of writing, almost without knowing it, perhaps I was in part making a case for my films as Creative Practice as Research. I always felt self-conscious about writing about my films as if I was engaged in self-promotion or exercising a justification, rather than applying analytical and theoretical tools I have developed in my years at universities. 


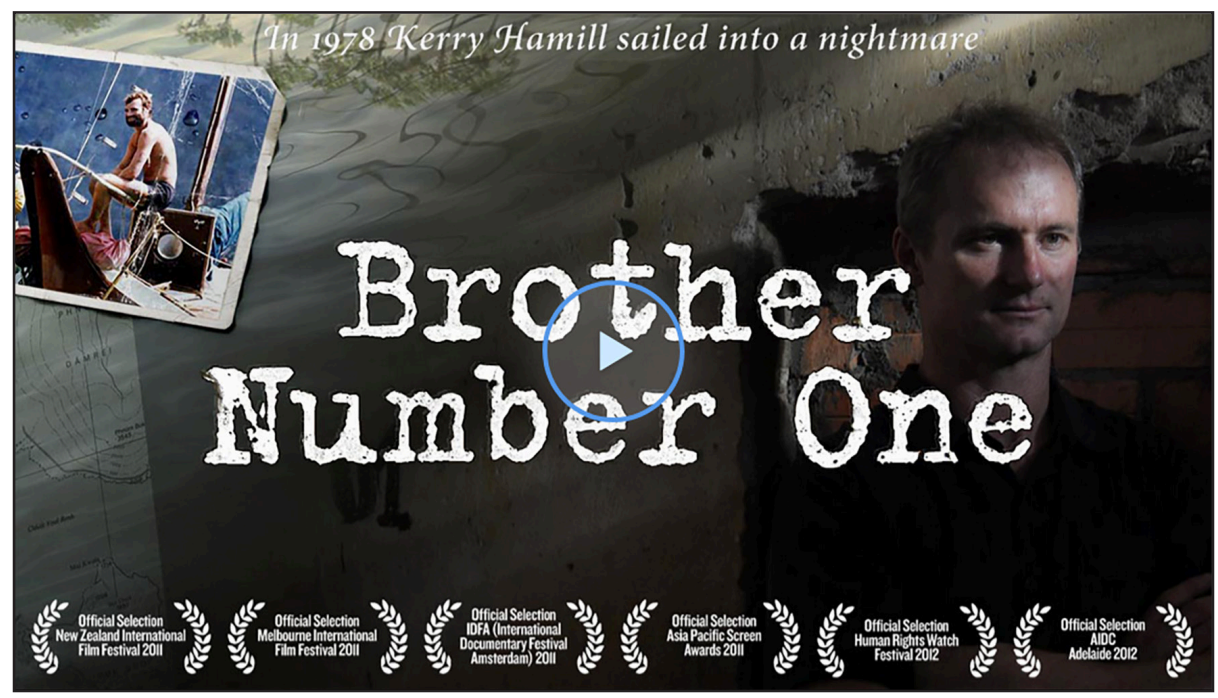

Figure 1: Brother Number One: An empathic connection or a bridge between Cambodian people and Western audiences. http://op.co.nz/

One such instance is an article I wrote after completing Brother Number One (2011), the feature documentary I directed and produced (along with Rob Hamill and James Bellamy). The film follows Rob Hamill's journey to Cambodia as he sought justice for his brother who had been tortured and murdered by the Khmer Rouge in 1978 (Figure 1). The article argues that as a character, Rob was able to provide an empathic connection or a bridge between Cambodian people and Western audiences, as the latter can feel distanced from the suffering of others (Goldson, 2014). Thus Brother Number One engages with critical issues about ethnography, 'othering' and dominant representation, a fraught topic within academic studies of documentary and anthropology as a discipline. Furthermore, the film's use of archive tells a brief history that explains, in part, the rise of the Khmer Rouge. It points to the involvement of the US, China and the Soviet Union, thus implicating the world's most powerful nations that used Cambodia as a pawn in a greater game, that permitted the rise of a brutal leadership. France, too, after its colonial rule ended, used its influence to keep the people undereducated, reliant on the whims of its 'Sun-King' Prince Sihanouk. Brother Number One then, as well as engaging with issues of representation, explores the history behind the rise of the regime, while allies it with disciplines such as anthropology, documentary studies and history.

My second example of an article (Goldson, 2015) explored two of my more recent films. He Toki Huna: NZ in Afghanistan (2013) looks at our most prolonged military engagement ever, asking three simple questions that have complicated answers: Why did we go into Afghanistan? What did we do there? Why did we 


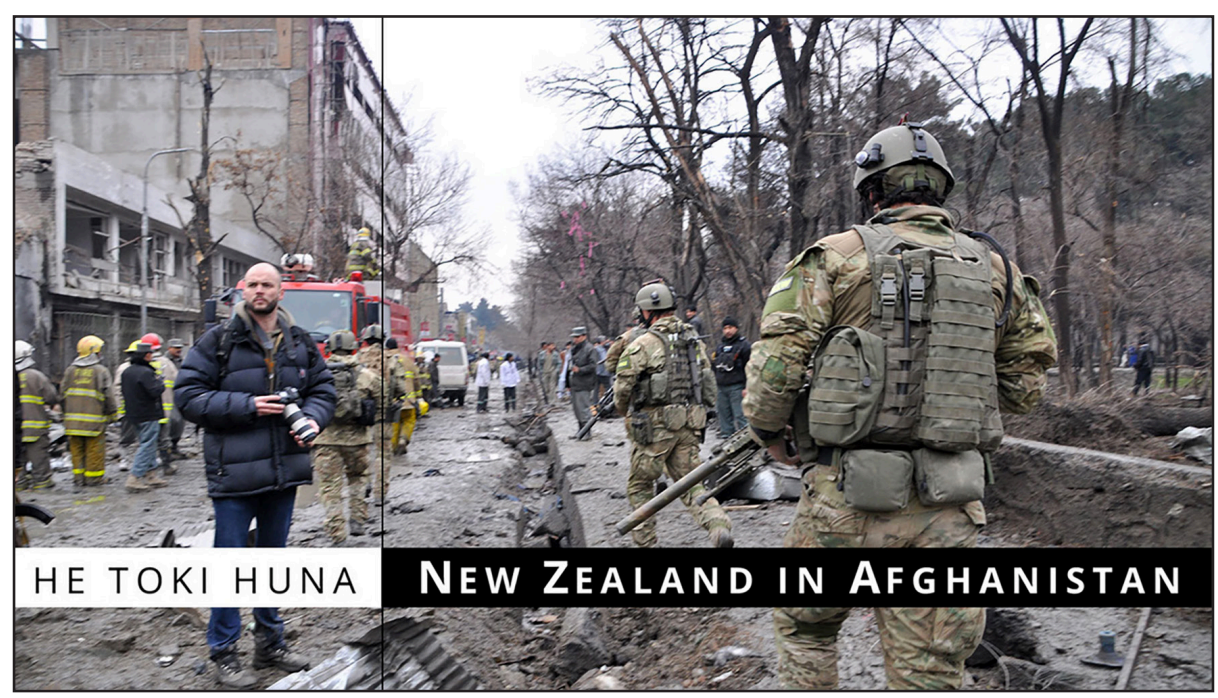

Figure 2: He Toki Huna: New Zealand in Afghanistan: Questions about media representation and political power. http://op.co.nz/

hear so little about it? The first two questions are aligned with those asked by disciplines such as politics and international relations, while the third engages with questions about media representation and political power (Figure 2). He Toki Huna then essentially mirrors Mike Wayne's point that a sizable sub-genre of documentary is involved in critiquing the mainstream media. Such films parallel 'academic criticism of ... television news and brings it into the mainstream' and 'exhibits the broader self-reflexive knowledge about media culture that is now in play' (2008, p. 90).

This second article also looks at my last completed film Kim Dotcom: Caught in the Web (Monsoon Pictures, 2017) which was accompanied by an ambitious online project kimdotcom.film. Caught in the Web followed the story of the notorious German hacker-turned-entrepreneur, who founded MegaUpload, a file-sharing platform which became massively popular. The New Zealand police arrested Kim Dotcom and three of his colleagues in a high-profile raid on the Dotcom mansion in 2012, accusing the team of pirating Hollywood films on a massive scale. Since that time, the online mogul has been facing, but has successfully fought, extradition to the US where he could face up to 80 years in prison. The film was challenging as the rollicking tale of Dotcom took quite some telling, requiring an extended editing period to craft a coherent story. Wayne (2008, p. 84) suggests above that 'narration' in a documentary is equivalent to a scholar's assessment of his or her research, a commentary if you like (Figure 3). Yet as with most of my documentaries, I did not use voiceover to tell the story, rather interwove elements of interview, archive, visual sequences and some graphic 


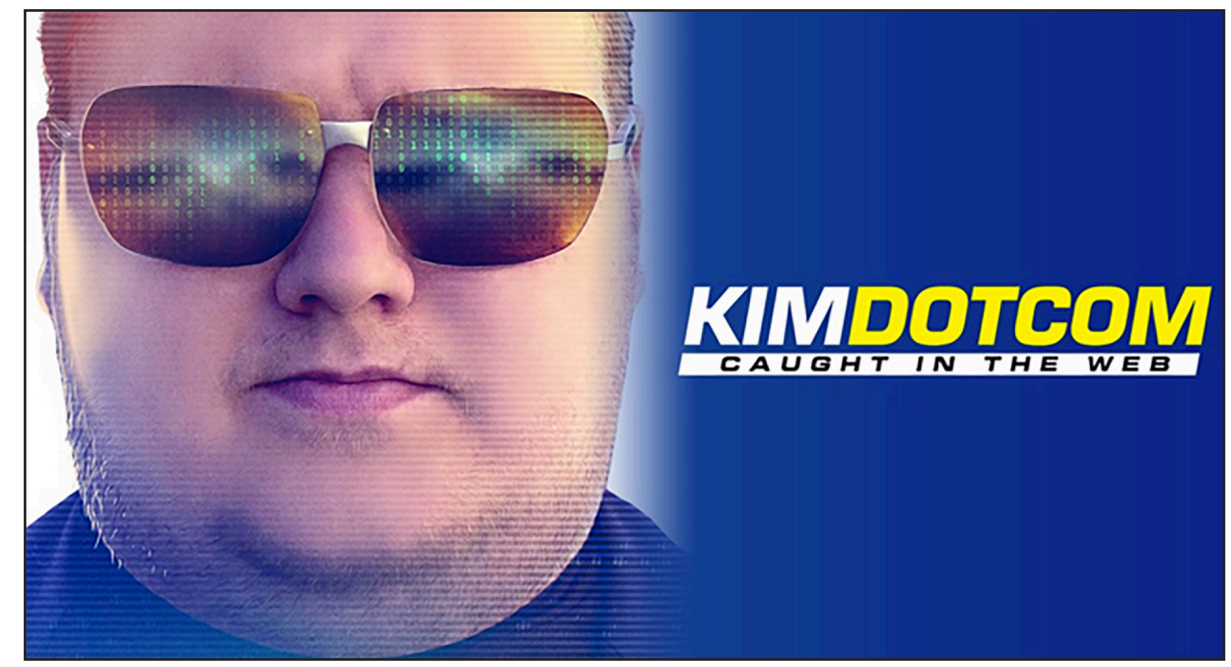

Figure 3: Kim Dotcom: Caught in the Web: 'Narration' in a documentary is equivalent to a scholar's assessment of his or her research, or a commentary. http://kimdotcom.film/

elements, along with an evocative music track. Such an approach is more allied with Nichols' (1983) idea of the 'voice of documentary':

By 'voice' I mean something narrower than style: that which conveys to us a sense of a text's social point of view, of how it is speaking to us and how it is organising the materials it is presenting to us. In this sense 'voice' is not restricted to any one code or feature such as dialogue or spoken commentary. Voice is perhaps akin to that intangible, moiré-like pattern formed by the unique interaction of all a film's codes, and it applies to all modes of documentary. (Nichols, 1983, p. 18)

Extending out from the narrative were commentaries on the recent history of, and themes critical to, the digital age. As I state in the article, the film also explores three key issues, relevant to us all, that underpin the Kim Dotcom case:

The first is how we consume and share media and information in a digital environment ... The second equally divisive issue that Dotcom case raises is that of surveillance .. Finally, in Caught in the Web, we will explore what the stakes are for New Zealand sovereignty as the Dotcom case plays out, given it sheds light on our relationship to the international community, and in particular, to the United States (Goldson, 2015).

\section{Conclusion}

I have attempted above to trace the history of Creative Practice as Research, drawing on my own experience and observations. The term, and its variants, 
arose about the same time as university auditing processes - the late 1990s, early 2000s. Practice has been part of some disciplines, but within the media arts, it has taken time for creative outputs to be recognised. Creative practitioners within academia face certain complications still, as they do outside the universities as they engage with their counterpart industries. The now-common usage of the term I argue is in part a greater recognition within the academy that cultural production can be research-rich providing 'new knowledge' to its respective fields. But its recognition has also been useful to the institutions themselves. Traditional universities can provide skills-based learning without losing a commitment to research, while the former polytechnics have extended their skills-training into more research-based pedagogies. My focus has been on documentary as that is where my experience lies - further reflections of how other cultural practices, such as fine arts, journalism or screenwriting, would be a welcome addition to the study of Creative Practice within the academy.

\section{Notes}

1. Creative Practice as Research is also known as Practice-Based Research, Practice as Research, Creative Practice Research or Non-traditional Research.

2. Performance-Based Research Fund https://www.tec.govt.nz/funding/funding-andperformance/funding/fund-finder/performance-based-research-fund/

3. http://papertiger.org/; https://archive.org/details/deepdishtv

4. In descriptive paragraph on the book's website: http://bitly.ws/7Y4W

5. In descriptive paragraph on the Intellect journal's website: https://bit.ly/3cCZiCw

\section{References}

Bacon, W. (2012). An innovative direction in academic journalism. Pacific Journalism Review. 18. 153-166. https://doi.org/10.24135/pjr.v18i2.270

Bacon, W. (2020). Submission to the Australian and NZ standard research classification review.

Dovey, John (2009). Making a difference: Media practice-as-research, creative economies and cultural economies. In Ludivine Allegue, et al. (Eds.), Practice-as-research in performance and screen. Hampshire and New York, NY: Palgrave MacMillan.

Gaines, J. and Renov, M. (Eds.) (1999). Collecting visible evidence. Minneapolis, MN: Minnesota University Press.

Goldson, A. (2011). Brother number one. BNO Productions.[Documentary]. http:// op.co.nz/

Goldson, A. (2014). Testimony and translation: tracing the past in Brother Number One. Studies in Documentary Film, 8(1), 2-20, DOI: 10.1080/17503280.2014.900709

Goldson, A. (2015). Journalism plus? The resurgence of creative documentary. Pacific Journalism Review : Te Koakoa, 21(2), 86-98. https://doi.org/10.24135/pjr.v21i2.120

Goldson, A., \& Ellmers, K. (2013). He toki huna: NZ in Afghanistan. [Documentary] Occasional Productions. http://op.co.nz/ 
Goldson, A. (2017). Kim Dotcom: Caught in the web. Monsoon International, produced by Behse, A. [Documentary]. http://kimdotcom.film/

Johnston, C. (1973). Women's cinema as counter-cinema. In C. Johnston (Ed.), Notes on Women's Cinema. London, UK: Society for Education in Film and Television.

Juhasz, A. (1999). They said we were trying to show reality - all I want to show is my video: the politics of the realist feminist documentary. In J. Gaines \& M. Renov (Eds.), Collecting visible evidence (pp. 190-215). Minneapolis, MN: Minnesota University Press.

Mayer, V., Banks, M., \& Caldwell, J. (2009). Production studies: Cultural studies of media industries. New York, NY: Routledge.

McHugh, S. (2019). Beyond journal articles: Navigating the NTRO. Retrieved from https://www.flowjournal.org/2019/04/beyond-journal-articles/comment-page-1/

Mulvey, L. (1975). Visual pleasure and narrative cinema. Screen. 16(3), 6-18. doi:10.1093/ screen/16.3.6.

Nash. C. (2016). What is journalism? The art and politics of a rupture. London, UK: Palgrave Macmillan.

Nash, C. (2017). Journalism, the question is ... Australian Journalism Review. 39(1), 25-29.

Nichols, B. (1983). The voice of documentary. Film Quarterly. 36(3). DOI: $10.2307 / 3697347$.

Renov, M. (1993). Theorizing documentary. New York, NY, \& London, UK: Routledge.

Robie, D. (2015). Advocating journalism practice-as-research: A case for recognition in the New Zealand PBRF context. Asia Pacific Media Educator. 25(1), 62-73. https:// doi.org/10.1177/1326365X15575591

Wayne, M. (2008). Documentary as critical and creative research. In T. Austin \& W. de Jong (Eds.), Rethinking documentary: New perspectives and practices (pp. 82-94). Austin, TX: McGraw Hill Education.

Dr Annie Goldson is a professor at the University of Auckland. She is a documentary filmmaker whose major titles Punitive Damage, Georgie Girl, Sheilas, Pacific Solution, Elgar's Enigma, An Island Calling, Brother Number One, He Toki Huna: New Zealand in Afghanistan and Kim Dotcom: Caught in the Web have screened widely at film festivals and on television worldwide.

Dr Goldson is also an academic, who publishes widely in books and journals and through her teaching, has mentored many younger filmmakers. She holds the New Zealand Order of Merit (ONZM) for services to film and was recently nominated for membership of the Royal Society of New Zealand.

a.goldson@auckland.ac. 